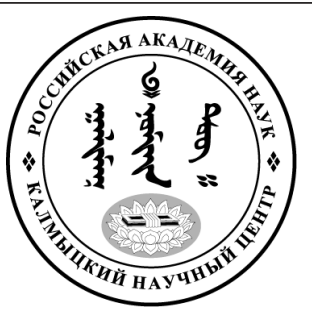

Published in the Russian Federation

Oriental Studies (Previous Name: Bulletin of the Kalmyk Institute

for Humanities of the Russian Academy of Sciences)

Has been issued as a journal since 2008

ISSN: 2619-0990; E-ISSN: 2619-1008

Is. 5, pp. $845-854,2019$

DOI: $10.22162 / 2619-0990-2019-45-5-845-854$

Journal homepage: https://kigiran.elpub.ru

УДК 902

\title{
К вопросу о социальной структуре населения Биктимировского могильника
}

\author{
Антон Сергеевич Проиееко ${ }^{1}$ \\ ${ }^{1}$ Республиканский историко-культурный музей-заповедник «Древняя Уфа» (д. 45, ул. Мустая Ка- \\ рима, 450077 Уфа, Российская Федерация) \\ научный сотрудник \\ ORCID: 0000-0002-5152-8564. E-mail: anton.procenko@mail.ru
}

\begin{abstract}
Аннотация. Введение. Исследование посвящено анализу материалов Биктимировского могильника (III-II вв. до н. э.) кара-абызской археологической культуры Южного Приуралья. Цели $u$ задачи исследования - на основе комплексного изучения погребального обряда осуществить реконструкцию социальной структуры населения. Материалы и методы. Наиболее информативным источником для реконструкции социальной структуры древнего общества являются погребальные памятники. В основу работы легли материалы 85 погребений, исследованных К. В. Сальниковым и А. Х. Пшеничнюком в 1960-е гг. Результаты. Автором проведена суммарная характеристика погребального обряда и проанализированы половозрастные группы древнего населения. Выявлено, что для мужской выборки характерно наличие предметов вооружения, для женской - предметов костюмного комплекса. Маркирующим признаком для женских захоронений является ожерелье из бус и пряслице, для мужских погребений - оселок. Для выяснения социальной структуры населения могильника погребения были распределены на пять категорий («очень богатые», «богатые», «рядовые», «бедные», «беднейшие») по количественно-качественному составу предметов. Статистика «богатых» и «очень богатых» захоронений позволяет предположить, что женщина имела более высокий статус в обществе. Bblводы. Исследования показали, что, несмотря на наличие незначительного имущественного расслоения, большинство сородичей имело равноправное положение в обществе.

Ключевые слова: кара-абызская культура, Биктимировский грунтовый могильник, социальная структура, погребальный обряд

Для цитирования: Проценко А. С. К вопросу о социальной структуре населения Биктимировского могильника. Oriental Studies. 2019;(5): 845-854. DOI: 10.22162/2619-0990-2019-45-5$845-854$
\end{abstract}

UDC 902

\section{Biktimirovo Burial Ground: Social Structure of the Ancient Population Revisited}

Anton S. Protsenko ${ }^{1}$

${ }^{1}$ Ancient Ufa Open-Air Reserve Museum of History and Culture (45, Mustay Karim St., Ufa 45450077, Russian Federation)

Research Associate 
ORCID: 0000-0002-5152-8564. E-mail: anton.procenko@mail.ru

Abstract. Introduction. The paper analyzes materials from Biktimirovo burial ground $\left(3^{\text {rd }}-2^{\text {nd }}\right.$ centuries BC) of the Kara-Abyz culture traced within the southern Cis-Urals. Goals and Objectives. The work seeks to comprehensively investigate the funeral rites and reconstruct the social structure of the ancient population. Materials and Methods. Burials and related attributes serve a most informative source to reconstruct social structures of ancient communities. The study examines 85 burials investigated by K. Salnikov and A. Pshenichnyuk in the 1960s. Results. The paper summarizes the funeral rites and analyzes age-sex groups of the ancient population. Burials of men are characterized by the presence of weapons, those of women - by garment elements. Bead necklaces and spindle whorls mark women's tombs, sharpening stones mark those of men's. The qualitative and quantitative compositions of burial attributes proved instrumental in dividing the whole of the buried community into 5 categories, such as the 'wealthy', 'rich', 'regular', 'poor' and 'poorest'. Statistics of the 'rich' and 'wealthy' makes it possible to suggest that woman enjoyed a higher status in society. Conclusions. The research results show that notwithstanding income inequality most tribesmen had equal social positions.

Keywords: Kara-Abyz culture, Biktimirovo burial ground, social structure, funeral rites.

For citation: Protsenko A. S. Biktimirovo Burial Ground: Social Structure of the Ancient Population Revisited. Oriental Studies. 2019;(5): 845-854. DOI: 10.22162/2619-0990-2019-45-5-845-854.

\section{Введение}

Биктимировский комплекс памятников расположен в Бирском районе Республики Башкортостан, в который входят городище и три грунтовых могильника, относящихся к одной из самых ярких этнических образований раннего железного века Предуралья кара-абызской археологической культуре.

I Биктимировский могильник находится на северной окраине д. Ново-Биктимирово на правом берегу р. Уряды, на котором в течение трех полевых сезонов (1962 г. раскопки К. В. Сальникова; 1963-1964 гг. А. Х. Пшеничнюка) исследованы 68 погребений.

II Биктимировский могильник находится в 300 м восточнее деревни, на восточном склоне Биктимировского городища, на правом берегу р. Белой. В 1958 г. А. П. Шокуровым обнаружены остатки 4 разрушенных весенними водами погребений. При их зачистке были найдены наконечники стрел и копий, бронзовые пряжки. В 1960 г. К. В. Сальниковым был заложен раскоп (6×2 м), выявлено ещё 2 погребения. Костяки лежали вытянуто, ногами к пойме р. Белой.

III Биктимировский могильник расположен на южной окраине д. Ново-Биктимирово на правом берегу р. Белой [АКБ 1976: 9697], на котором А. Х. Пшеничнюк в 1964 г. исследовал 17 погребений.

В связи с тем, что I Биктимировский могильник расположен на северной окраине деревни, а III Биктимировский - на южной, А. Х. Пшеничнюк предположил, что это один могильник. Разделяющий их участок протяженностью в 600-700 м, занятый огородами и постройками, не раскапывался [Пшеничнюк 1973: 167], данной точки зрения мы придерживаемся в своем исследовании.

В общей сложности на сегодняшний момент на I и III Биктимировских могильниках изучено 85 погребений, датируемых III-II вв. до н. э., которыми мы оперируем в своем исследовании. Общая характеристика материалов и погребального обряда могильника (раскопки 1962-1963 гг.) дана в публикациях автора стационарных раскопок памятника [Пшеничнюк 1964б].

Из 47 раскопанных и опубликованных погребений Биктимировского могильника, непотревоженными оказались 28 , в том числе 7 детских. Остальные разрушены либо в результате ограбления в древности (14 погребений), либо при сооружении силосных траншей (5 погребений) [Пшеничнюк 1964б: 215]. Необходимо отметить, что часть материалов до сих пор не опубликована.

Половозрастная принадлежность определялась авторами раскопок исключительно исходя из сопроводительного инвентаря погребенных. Позднее М. С. Акимовой были опубликованы антропологические определения, из раскопок 1962-1963 гг. серия включала 7 мужских, 6 женских и 1 детский череп. Женские погребения представлены: 
погр.18 (20-25 лет), погр. 20 (возраст не определен), погр. 22 (35-40 лет), погр. 37 (25-30 лет), погр. 46 (25-30 лет), погр. 47 (40-50 лет). Мужские погребения: погр. 2 (35-40 лет), погр. 12 (40-45 лет), погр. 25 (30-35 лет), погр. 26 (50-60 лет), погр. 33 (30-35 лет), погр. 41 (40-50 лет), погр. 44 (35-45 лет) [Акимова 1968: 20-29]. Таким образом, на данный момент имеем 16 \% захоронений от общего числа исследованных погребений, у которых пол и возраст определен профессиональным антропологом.

Данные погребения стали эталонами для определения комплексов мужских и женских захоронений. К женским относились погребения, которые сопровождались набором украшений, к мужским - главным образом предметами вооружения.

\section{Постановка вопроса}

Актуальность данной работы вызвана тем, что, несмотря на столетнюю историю изучения погребальных комплексов караабызской культуры, на которых вскрыто свыше 1400 захоронений [Проценко 2016: 45], специальных исследований по социальной организации не проводилось. В свою очередь отметим, что исследования по данной проблематике населения раннего железа Прикамья и Предуралья, несмотря на наличие определенных кризисных явлений [Проценко 2012], на современном этапе становятся неотъемлемой частью археологического исследования [Журавлева, Байкова 2016].

Цель настоящей работь - комплексное изучение сопроводительного инвентаря и погребальных конструкций захоронений для выявления социальных групп и рассмотрения социальной структуры населения, оставившего данный некрополь.

На первом этапе нами была проведена суммарная характеристика погребального обряда Биктимировского могильника. Общая характеристика исходных признаков погребального обряда в настоящей работе опирается на данные по 87 индивидам (мужчины - 22, женщины - 22, дети 11 , пол и возраст не определен - 32) из 85 захоронений. Ассортимент и содержание признаков погребального обряда определялись исключительно теми сведениями, которые приводят исследователи памятника в своих научных отчетах или публикациях. Среди них объективными, т. е. с точки зре- ния археологического источниковедения, реально фиксируемыми являются тип и планиграфия могильника, способ захоронения, ориентировка и поза погребенного, детали ритуала, ассортимент погребального инвентаря. Необходимо отметить, что суммарная характеристика погребального обряда кара-абызской культуры проведена автором настоящего исследования [Проценко 2017; Иванов, Проценко 2017].

\section{Основная часть}

Погребальный обряд Биктимировского могильника характеризуется следующими признаками: захоронения совершались по обряду ингумации в простых могильных ямах, четырехугольной формы с закругленными углами. Глубина от современной поверхности варьировалась от 0,5 (8,2 \%) до 1 м (36,5\%), 1-1,5 м (47\%) или более 1,5 м $(8,2 \%)$. Деревянная подстилка (древесная кора) зафиксирована в $13 \%$ погребений (от общего количества анализируемых погребений), вероятно, умерших завертывали в лубок [Пшеничнюк 1964б: 217].

В большинстве могил захоронен один погребенный, парные погребения отсутствуют, лишь в погр 13 III Биктимировского могильника погребены три индивидуума. Глубина могильной ямы - 0,8 м, погребенные (костяки взрослых людей) были уложены на спинах, головами на восток. Кисти рук костяка № 1 (у северной стенки) покоились на бедрах, у остальных - вытянуты.

Инвентарь представлен в основном бронзовыми наконечниками стрел. При костяке № 1 найдено семь наконечников: пять между коленными суставами и один слева у черепа; при костяке № 2 - два наконечника: один слева у черепа, другой - между коленными суставами; при костяке № 3 два наконечника: один на груди, справа и один снаружи левого бедра. Возле костяка № 3 у левой кисти найдена медная бляшка и обломок кости животного [Пшеничнюк 1964a: 16-17].

Умерших людей традиционно укладывали вытянуто на спине, головой на запад (27 \%), к ним следует добавить 18,8 \% умерших, лежавших головой на северо-запад $(18,8 \%)$ и $10,5 \%$ - на юго-запад, что суммарно составляет 56,3 \%. Ориентировка не установлена в 21,1\%. 
В качестве ритуальных предметов в погребениях в единичных случаях были обнаружены сосуды, установленные в двух случаях: в изголовье и в засыпке могилы. Кости животных зафиксированы в одном погребении в изголовье, а в другом - точное местонахождение относительно костяка определить не удалось. Самым популярным из ритуальных веществ был мел, который зафиксирован в восьми погребениях.

Ассортимент погребального инвентаря представлен предметами вооружения: удила $(3,5 \%)$, наконечники стрел: железные $(4,7 \%)$, бронзовые $(28,2 \%)$ и костяные $(3,5 \%)$, колчанный крючок $(4,7 \%)$, боевой нож $(3,6 \%)$, наконечник копья $(10,6 \%)$. В погр. 31 I Биктимировского могильника [Пшеничнюк 1963], у правого бедра был найден железный меч серповидной формы. В большом количестве представлены предметы украшений и костюмного комплекса: поясные накладки $(11,7 \%)$; накладки ремня зооморфные (10\%); наконечник пояса $(2,4 \%)$; пряжки - кольцевая $(3,5 \%)$, зооморфная $(2,4 \%)$, других форм (10,6\%); пояс цельный находился у 5,9 \% погребений; портупея (11,8\%); обоймы $(18,8 \%)$; дисковидные бляхи $(11,8 \%)$; мелкие круглые бляшки $(24,7 \%)$; бляха умбоновидная $(2,3 \%)$; серьга-кольцо $(8,2 \%)$; подвески трапециевидные (9,4\%); перстень (14,1\%); браслет (2,3\%); 1-5 бусин (13\%); ожерелье $(16,5 \%)$; пронизки $(12 \%)$. Единично представлены эполетообразные застежки и зооморфные подвески. Из бытовых предметов доминирующее положение занимают ножи (27 \%), в незначительном количестве представлены оселки и пряслица.

Далее остановимся на анализе погребений, которые могут быть отнесены к одной из половозрастных групп. Половозрастной анализ представляет собой часть социального анализа и один из этапов исследования общественных отношений. Индивидуум первобытности достаточно отчетливо ощущал свой переход в очередной возрастной, а вместе с ним и очередной статус [Бунятян 1985: 58].

Мужские погребения (22 погребения). Умершие лежат на спине, с вытянутыми конечностями, за исключением погр. 31 , где у покойного правая нога согнута в колене. Превалирует западная $(23,7$ \%) или северо-западная $(20,3 \%)$ ориентировка, глуби- на могил в большинстве случаев составляет 1-1,5 м (42,2 \%). Ритуальные признаки представлены: фрагментами лепной керамики (погр. 25) обнаруженными в засыпке могилы, и двумя кусочками мела у правых берцовых костей из погр. 12 I Биктимировского могильника.

Интересные находки происходят из погр. 53, в котором найден просверленный клык кабана (?), и погр. 14 III Биктимировского могильника, где в области пояса находились подвески или ожерелье из зубов животных и две костяные трубочки.

Сопроводительный инвентарь в основном представлен предметами вооружения: бронзовыми (33\%), железными $(6,4 \%)$ и костяными (5\%) наконечниками стрел; наконечником копья $(14,4$ \%). Единично представлены такие категории инвентаря, как удила, колчанный крючок, кинжал, железный меч, боевой нож и железное шило.

Немногочисленны и элементы костюмного комплекса: наконечник пояса (3,1 \%), кольцевая пряжка (5\%), мелкие круглые бляшки (11\%), перстень (6,4\%), бусины от 1 до 4 штук (12\%) и пронизки $(9,6 \%)$. В трех погребениях обнаружены височные подвески или серьги [Пшеничнюк 1964б: 226]. Из бытовых предметов зафиксирован нож $(24 \%)$. Отметим, что оселок был расположен на крестце и найден исключительно в мужских погребениях: погр. 10, 14 III Биктимировского и погр. 58 I Биктимировского могильника.

Инвентарь отсутствовал в погр. 33 I Биктимировского могильника, где был захоронен мужчина (30-35 лет). Необходимо отметить весомую долю погребений (8), в которых зафиксированы следы ограбления в древности.

В целом мужская выборка характеризуется большим числом умерших с предметами вооружения. Сравнение мужской выборки по возрастным когортам невозможно в связи с малочисленностью половозрастных определений и разграблением погребений в древности.

Женские погребения (22 погребения). Захороненные уложены аналогично мужским погребениям. Глубина могил в 64 \% составляет 1-1,5 м, так же, как и у мужчин, доминирует западная ориентировка (41\% погребенных). В 31,8 \% фиксируется дощатый настил (древесная кора). 
Несколько отличаются по своему устройству могильные ямы погр. 46 и 47. В начале для них была вырыта обширная подквадратная общая могильная яма, ориентированная по сторонам горизонта. На глубине 110 см от поверхности яма была поделена материковой перемычкой шириной 40 см на две обычные могильные ямы, углубленные ещё на 40 см и ориентированные по линии восток-запад [Пшеничнюк 1964б: 217]. В качестве ритуальных признаков в погр. 32 в засыпке могилы найдены два сосудика из глины с растительной примесью: один - в виде курильницы на поддоне, второй - круглодонная чашечка с ушками для подвешивания, украшенная одним рядом круглых ямок [Пшеничнюк 1963: 9]. В семи погребениях найдены по одному или по два кусочка мела. А. Х. Пшеничнюк считал, что данный обычай перенят у сарматов, так же, как и ритуальный сосудик на поддоне, описанный выше, находит аналогии среди посуды прохоровской культуры [Пшеничнюк 1964б: 230]. Остатки сопроводительной пищи зафиксированы в погр. 37, внутри правого плеча лежали две кости животного.

Сопроводительный инвентарь представлен предметами костюмного комплекса: поясные накладки (45 \%), накладки ремня зооморфные (с изображением голов грифонов) в девяти погребениях, пряжки других форм (18\%), пояс цельный (18 \%), портупея (41\%), обоймы (68\%), большая круглая бляха (45 \%), мелкие круглые бляшки (68 \%), подвески трапециевидные $(31,8 \%)$. Перстни обнаружены в $40 \%$ женских захоронений, браслеты - в $9 \%$, пронизки - в $18 \%$. В отличие от мужских находок, бусы представлены весьма широко: в $50 \%$ в составе ожерелья и в трех погребениях в количестве от 1 до 5. Единично обнаружены: в трех погребениях подвески в виде колокольчиков, пряжки зооморфные (со стилизованным изображением оленей) и подвески-лунницы.

Из бытовых предметов наиболее часто встречаются железные ножи (41\%) и глиняные пряслица -4 экз. Предметы вооружения, хотя и не считаются женским сопутствующим инвентарем, тем не менее найдены в 3 случаях. В погр. 17 молодой женщины (20-25 лет) в области пояса найден железный кинжал с остатками дерева на рукояти, и снаружи у левого колена острием вниз лежали 7 бронзовых трехлопастных наконечников стрел [Пшеничнюк 1963: 2]. В погр. 32 в центре могилы - бронзовый трехлопастной наконечник стрелы. Погр. 39 - бронзовые наконечники стрел служили язычком для трех подвесок-колокольчиков [Пшеничнюк 1964б: 219].

Сопроводительный инвентарь отсутствовал лишь в одном захоронении (погр. 20).

Сравнительная характеристика женской выборки по возрастным когортам позволяет сделать несколько предварительных выводов. Предметы вооружения (железный кинжал и бронзовые наконечники стрел) были уложены в могилу только у молодой женщины (20-25 лет) в погр. 18, что может говорить о том, что в случае необходимости женщины выполняли и воинскую роль. Женщинам старшего возраста 25-30 лет (погр. 37 и 46), 35-40 лет (погр. 22) и 4050 лет (погр. 47) было принято класть в могилу большое количество украшений. По материалам Биктимировских некрополей А. Х. Пшеничнюком был реконструирован женский костюм [Пшеничнюк 1964б: 225, рис. 6], который ярко показывает данный феномен. При явном следовании стандарту в ориентировке погребенных (головой на запад) необходимо отметить погр. 18 с северо-восточной ориентировкой, в котором содержались предметы вооружения, что, на наш взгляд, связано с ее профессиональной деятельностью (женщина-воительница). Безусловно, женскими деталями украшения следует признать бусы в ожерельях и глиняные пряслица, поскольку они полностью отсутствуют в мужских погребениях и представлены в женских.

Детские погребения (11 погребений). Во всех погребениях, в которых удалось проследить положение костяков, они лежали на спине, вытянуто. Ориентировка в большинстве погребений западная (7 погр.), ногами к реке, единичны погребения с северной и восточной ориентировкой. В качестве ритуальных признаков в погр. 8 найдены три кусочка мела - один ниже остатков черепа и два у ног [Сальников 1962: 39] и один в погр. 21. Остатки сопроводительной пищи или керамической посуды, которая фиксируется на других некрополях кара-абызской культуры [Иванов, Проценко 2017: 124], не обнаружены. 
Выделяется заметная группа безынвентарных погребений -6 захоронений.

Вещевой инвентарь не слишком разнообразен. В трех погребениях были найдены несколько бусин (от 1 до 4), по одному экземпляру представлены железный нож и железное колечко небольшого размера.

Особняком стоят два погребения, которые отличались количеством и качеством сопроводительного инвентаря. В погр. 21 находились две умбоновидные бронзовые бляшки с ушком на обороте, кусочек мела, обломок железного ножа (?), бронзовые обоймицы (4 экз.), бусы - 10 гешировых плоских и 9 из золоченого стекла. Под костяком найдены бронзовые перстень и трапециевидная подвеска [Пшеничнюк 1963: 8]. В погр. 63: у черепа найдено несколько бусин и медная бляшка, по одной подобной бляшке найдено по бокам в середине могилы, в западной половине могилы обнаружено маленькое железное колечко [Пшеничнюк 1964а: 8].

Необходимо отметить и нестандартную ориентировку в данных захоронениях юго-восточную (погр. 21) и восточную (погр. 63). Костяки были уложены прямо противоположно основной части детских захоронений, головой к реке. Скорее всего, данные захоронения принадлежали к наиболее богатым семьям рода, чьи дети и были в ней погребены.

Определить пол и возраст не удалось в 30 захоронениях, в 13 случаях (43,3 \%) сопроводительный инвентарь отсутствовал. По одной категории находок зафиксировано в десяти погребениях: бронзовые наконечники стрел в количестве от одного до трех содержались в четырех погребениях; единичные находки бус в двух погребениях и по одному артефакту было найдено в погр. 48 (небольшой сосуд); погр. 54 (два бесформенных сильно окисленных кусочка железа), погр. 56 (железное колечко), погр. 60 (бронзовая бляшка).

Два предмета содержали пять захоронений: погр. 4 (бронзовый наконечник стрелы и железный нож), погр. 13 (7 наконечников стрел, медная бляшка) и три погребения III Биктимировского могильника: погр. 9 (3 бронзовых наконечника стрелы и железный нож), погр. 11 (7 бусин и височное кольцо), погр. 12 (два височных кольца, бронзовая бляшка).
Три и более предмета содержали четыре захоронения: погр. 23 (серебряная бляшка с отверстием в центре, бронзовая пронизка и обломок железного крючка), погр. 59 (бронзовые накладки, круглые бляшки, подвеска), погр. 64 (бронзовый наконечник стрелы, 15 бронзовых пронизок, серебряный перстень), погр. 66 (глиняный сосуд, 11 бусин, 6 бронзовых пронизок).

Группа безынвентарных погребений составляет $26 \%$. Из 22 захоронений, в которых отсутствует сопроводительный инвентарь, пол и возраст определен у трех костяков: погр. 7 (детское, 14-15 лет), погр. 20 (женское, 20-25 лет) и погр. 33 (мужское, 30-35 лет) Биктимировского могильника [Акимова 1968: 21]. Из захоронений, не содержащих сопроводительного инвентаря, выделяется погр. 9, костяк которого был уложен на левом боку, левая рука согнута, кисть у нижней челюсти; правая - полусогнута, кисть на левом бедре [Сальников 1962: 39].

Несмотря на плотное расположение могильных ям, на некоторых участках могильника зафиксирован только один случай нарушения могильной ямы друг другом, что говорит не только о небольшом хронологическом разрыве между погребениями, но и о наличии каких-то надмогильных сооружений. Планиграфически выделяются детские погребения, которые сконцентрированы в восточной части некрополя, также А. Х. Пшеничнюком были отмечены захоронения, которые расположены рядами [Пшеничнюк 1964б: 216, рис. 1; 217], но они немногочисленны.

\section{Обсуждение результатов}

Анализ материала показывает, что погребальный обряд населения, оставившего Биктимировский могильник, представляет собой целостную и специфическую для данной культуры систему, созданную для заботы об умершем.

В то же время сравнение мужской и женской выборки позволяет отметить некоторые различия. Во-первых, мужские погребения патриархального общества традиционно маркируются оружием, так же как, к примеру, и мужское население раннесарматской культуры [Балабанова и др. 2015: 33]. Хотя женщины также участвуют в военных действиях, но в связи с тем, что оружие найдено только в одном женском погребении, дан- 
ная гипотеза нуждается в подтверждении. Во-вторых, женские погребения сопровождает богатый набор украшений, что показывает достаточно высокий статус женщины в кара-абызском обществе (III-II вв. до н. э.). Железный нож является универсальным предметом и встречается в большинстве погребений обоих полов. Необходимо отметить, что значительное число мужских погребений было ограблено в древности, в то же время процент ограбленных женских захоронений значительно ниже.

Детские погребения в погребальном обряде демонстрируют общую ритуальную традицию. Захоронения производились в одной манере со взрослыми, но в сопровождении более скудного инвентаря, что, скорее всего, обусловливалось имущественным (социальным) положением ребенка.

Для выяснения социальной структуры населения могильника погребения были распределены на пять категорий («очень богатые», «богатые», «рядовые», «бедные», «беднейшие») по количественно-качественному составу предметов. Данный способ позволяет проанализировать внутренние связи вещей в комплексах погребений и попытаться в определенной степени отразить через предметный мир социальные группы населения, а также определить возможные роли мужчин и женщин в обществе [Казанцева 2014: 110].

Сложнее всего определить и выделить «бедные» погребения. Поскольку основным критерием для их выделения является качество и количество сопровождающего инвентаря, здесь необходимо учитывать и факт ограблений погребений в древности. Поэтому в нашем случае среди женских погребений формально к категории «бедные» были отнесены четыре погребения, но все они были ограблены в древности. «Рядовые» - самые многочисленные - насчитывают семь захоронений. Критерием для выделения «очень богатых» и «богатых» погребений являлось не только количество вещей в могиле, а именно качество (оригинальность изделия) или наличие предмета из драгоценного металла (например, височное кольцо из золотой проволоки в виде спирали в 2,5 оборота). «Богатых» комплексов насчитывается пять, «очень богатых» - пять. И одно погребение, не содержащее сопроводительный инвентарь, можно отнести к категории «беднейших».
В мужских могилах к категории «беднейших» отнесено одно погребение, «бедных» насчитывается пять погребений, три из которых были ограблены в древности. «Рядовые» захоронения наиболее многочисленны - девять погребений, из которых три ограблено. Среди данной категории выделяется погр. 12 (40-45 лет), в котором, наряду с двумя лигнитовыми бусинами и железным ножом, была обнаружена бронзовая круглая бляха-зеркало с четырьмя отверстиями по краям с обломанным краем и два кусочка мела [Сальников 1962: 40]. Последние две находки встречались только в данном мужском погребении, в остальных случаях подобные бляхи и кусочки мела фиксируются исключительно в женских захоронениях.

Категория «богатых» могил насчитывает пять погребений, сопроводительный инвентарь в них представлен 4-5 предметами (например, бронзовые наконечники стрел, наконечник копья, поясная пряжка, удила) и наличием предмета из драгоценного металла (например, височная подвеска в виде кольца с трубицей из золотой проволоки). Наиболее статусная категория - «очень богатые» - представлена одним захоронением (погр. 53).

Необходимо отметить, что категории «богатых» и «очень богатых» погребений в мужских и женских могилах значительно отличаются как по «качеству», так и по количеству сопроводительного инвентаря. Если в мужских погребениях сопроводительный инвентарь представлен в основном предметами вооружения и несколькими деталями костюма, то женские захоронения содержат значительно больше предметов. К примеру, мужской поясной набор, как уже было отмечено исследователями, отличался значительной простотой [Воробьева 2019: 53] и состоял в основном из одной пряжки. В то же время в женском костюме пояса состояли из дисковидных блях и накладок с изображением голов грифонов. Остатки древесной коры обнаружены в 8 захоронениях (всего на могиле зафиксировано 11 случаев) на дне могилы и фиксируются в категории «богатых» и «очень богатых»: в шести случаях у женщин и в двух - у мужчин, что, по нашему мнению, свидетельствует об особом погребальном обряде данных категорий захоронений. Ориентировка погребенных в данных двух категориях - западная, выде- 
ляется только женское погр. 39, в котором костяк был уложен в северо-восточном направлении.

Группу погребений, в которых определить пол и возраст не удалось, можно разделить на две категории: 13 погребений, в которых сопроводительный инвентарь отсутствовал, - «беднейшие», «бедные» могилы (в составе 2-4 предметов) содержатся в 17 захоронениях.

В результате мы получаем следующие данные по выделенным категориям: «беднейшие» - 15 захоронений, «бедные» 26, «рядовые» - 16, «богатые» - 11 , «очень богатые» - 6 захоронений. Выделенные группы могил отражают структуру населения памятника, но поскольку выборка имеет ограничения - не для всего массива погребений получены половозрастные определения - наши выводы носят сугубо предварительный характер.

\section{Выводы}

Отмеченное исследователями наличие у кара-абызского населения имущественного расслоения и сравнительно равноправное положение большинства сородичей [Пшеничнюк 1973: 216; Овсянников 2009: 245] находит свое подтверждение и в нашем исследовании, так же, как и точка зрения В. А. Иванова, который указывал, что материалы мужских погребений Биктимировского I могильника не дают оснований о специальном выделении воинских могил на территории некрополя. Исследователь отмечал снижение общественной значимости родоплеменных вождей в связи со стабилизацией общеполитической обстановки в регионе [Иванов 1984: 80-82].

В ходе анализа было выявлено, что погребальные конструкции, пол умершего и сопроводительный инвентарь позволяют обозначить группы населения разного социального статуса. Результаты показали, что сопроводительный инвентарь женских захоронений значительно превосходит в качественно-количественном отношении мужские погребения.

В настоящее время сложно говорить о наличии у «кара-абызцев» патриархального рабства. В частности, потому, что группа «беднейших» погребений по своим морфологическим признакам (положение и ориентировка покойного в могиле) ничем не выделяется от остальных. Несомненно, на сегодняшний день назрела необходимость в проведении исследований по демографии кара-абызских могильников. В сложившейся ситуации целесообразным представляется обращение к успешному опыту коллег, получивших интересные результаты по палеодемографии могильников пьяноборской культуры [Куфтерин, Воробьева 2019]. Некоторую информацию о структуре древнего общества даст и анализ планиграфии Биктимировских могильников, что, по нашему мнению, является темой для самостоятельного исследования. Дальнейшее изучение социальной структуры кара-абызской культуры позволит проанализировать эволюцию социально-экономических отношений оседлого лесостепного населения Южного Приуралья в раннем железном веке.

\section{Источники}

Пшеничнюк 1963 - Пшеничнюк $A$. X. Научный отчет об археологических исследованиях в центральных районах Башкирской АССР за 1963 г. // Научный архив Уфимского федерального исследовательского центра РАН. Ф. 3. Оп. 2. Д. 585.23 л.

Пшеничнюк 1964 a - Пшеничнюк $A$. X. Научный отчет о результатах археологической экспедиции за 1964 год // Научный архив Уфимского федерального исследовательского центра РАН. Ф. 3. Оп. 2. Д. 639. 46 л.

Сальников 1962 - Сальников К. В. Научный отчет о результатах археологической экспедиции за 1962 год по теме № 41 «Эпоха бронзы и железа в Башкирии», раздел «Эпоха бронзы Южного Урала» // Научный архив Уфимского федерального исследовательского центра РАН. Ф. 3. Оп. 2. Д. 562.50 л.

\section{Sources}

Pshenichnyuk A. Kh. [Scientific Report Summarizing Archeological Investigations in Central Bashkiria: 1963]. At: Ufa Federal Research Centre of the RAS, Scientific Archive. Fond 3. Ser. 2. File 585. 23 p. (In Russ.)

Pshenichnyuk A. Kh. [Scientific Report Summarizing Results of the Archeological Expedition: 1964]. At: Ufa Federal Research Centre of the RAS, Scientific Archive. Fond 3. Ser. 2. File 639. 46 p. (In Russ.)

Salnikov K. V. [Scientific Report Summarizing Results of the 1962 Archaeological Expedition, Theme No. 41 'Bronze Age in the Southern 
Urals']. At: Ufa Federal Research Centre of the RAS, Scientific Archive. Fond 3. Ser. 2. File 562. 50 p. (In Russ.)

\section{Литература}

Акимова 1968 - Акимова M. C. Антропология древнего населения Приуралья. М.: Наука, 1968. $119 \mathrm{c}$.

АКБ 1976 - Археологическая карта Башкирии / отв. ред. О. Н. Бадер. М: Наука, 1976. 264 с.

Балабанова и др. 2015 - Балабанова М. А., Клепиков В.М., Коробкова Е.А., Кривошеев М. В., Перерва Е. В., Скрипкин А. С. Половозрастная структура сарматского населения Нижнего Поволжья: погребальная обрядность и антропология. Волгоград: Изд-во Волгоградского филиала ФГБОУ ВО РАНХиГС, 2015. 272 с.

Бунятян 1985 - Бунятян Е. П. Методика социальных реконструкций в археологии на материале скифских могильников IV-III вв. до н. э. Киев: Наукова думка, 1985. 121 с.

Воробьева 2019 - Воробьева С. Л. Типы костюмных комплексов носителей кара-абызской эпохи раннего железа // Археология евразийских степей. 2019. № 1. С. 50-69.

Журавлева, Байкова 2016 - Журавлева Г. Н., Байкова A. K. Вопросы социальной структуры древнего населения в работах археологов Прикамья // Археологическое наследие Урала: от первых открытий к фундаментальному научному знанию (XX Уральское археологическое совещание). Ижевск: Институт компьютерных исследований, 2016. C. $18-20$.

Иванов 1984 - Иванов В. А. Вооруженное дело финно-угров Приуралья в эпоху раннего железа. М.: Наука, 1984. 88 с.

Иванов, Проценко 2017 - Иванов В. А., Проценко $A$. C. Погребальный обряд как индикатор генетической преемственности культур эпохи раннего железного века Прикамья и Предуралья // Археология евразийских степей. 2017. № 1. С. 117-129.

Казанцева 2014 - Казанцева О. А. К вопросу о социальной структуре населения Кудашевского I могильника (по результатам гендерного анализа) // Вестник Удмуртского университета. Серия «История и филология». 2014. № 3. С. 108-113.

Куфтерин, Воробьева 2019 - Куфтерин В. В., Воробьева С. Л. К палеодемографии пьяноборской культуры // Поволжская Археология. 2019. № 1 (27). С. 164-179.
Овсянников 2009 - Овсянников В. В. Караабызская культура (V в. до н. э. - IV в. н. э.) // История Башкирского народа: в 7 т. / гл. ред. М. М. Кульшарипов. М.: Наука, 2009. C. $223-245$.

Пшеничнюк 19646 - Пшеничнюк $A$. X. Биктимировский могильник // Археология и этнография Башкирии. Т. II. Уфа: ИИЯЛ БФАН, 1964. С. 215-231.

Пшеничнюк 1973 - Пшеничнюк A.X. Караабызская культура (население центральной Башкирии на рубеже нашей эры) // Археология и этнография Башкирии. Т. V. Уфа: ИИЯЛ БФАН, 1973. С. 162-243.

Проценко 2012 - Проценко А. С. Вопросы социальной реконструкции древних обществ в археологии Прикамья и Приуралья в раннем железном веке. Историографический аспект // Труды КАЭЭ. Вып. 8. Пермь: ПГГПУ, 2012. C. 177-181.

Проценко 2016 - Проценко А. С. Погребальные комплексы кара-абызской культуры (очерк истории накопления источниковой базы) // Клио. 2016. № 9 (117). С. 43-47.

Проценко 2017 - Проиенко А. С. Суммарная характеристика погребального обряда караабызской культуры // V (XXI) Всероссийский археологический съезд: сб. науч. тр. Барнаул: Алтайский гос. ун-т, 2017. С. 854855.

\section{References}

[Archeological Map of Bashkortostan]. O. N. Bader (ed.). Moscow: Nauka, 1976. 264 p. (In Russ.)

Akimova M. S. [Ancient Population of the CisUrals: Anthropology]. Moscow: Nauka, 1968. 119 p. (In Russ.)

Balabanova M. A., Klepikov V. M., Korobkova E. A., Krivosheev M. V., Pererva E. V., Skripkin A. S. [Age-and-Sex Structure of the Lower Volga Sarmatian Population: Funeral Rites and Anthropology]. Volgograd: Volgograd Branch of RANEPA, 2015. 272 p. (In Russ.)

Bunyatyan E.P. [Methodology of ArchaeologyRelated Social Reconstructions: a Case Study of Scythian Burial Grounds $\left(4^{\text {th }}-3^{\text {rd }}\right.$ Millennia BC)]. Kiev: Naukova Dumka, 1985. 121 p. (In Russ.)

Ivanov V. A. [Early Iron Age Weaponry of the Finno-Ugric Peoples]. Moscow: Nauka, 88 p. (In Russ.)

Ivanov V. A., Protsenko A.S. Funeral ceremony as an indicator of the genetic continuity of the cultures of the Early Iron Age in the Kama 
River and the Cis-Urals Region. Archaeology of the Eurasian Steppes. 2017. No. 1. Pp.117-129. (In Russ.)

Kazantseva O. A. On the problem of the social structure of the population in the Kudashevsky I cemetery (the results of the gender analysis). Bulletin of Udmurt University. Series 'History and Philology'. 2014. No. 3. Pp. 108-113. (In Russ.)

Kufterin V. V., Vorobyeva S. L. On the paleodemography of Pyany Bor culture. Povolzhskaya Arkheologiya - The Volga River Region Archaeology. 2019. No. 1(27). Pp. 164179. (In Russ.)

Ovsyannikov V. V. Kara-Abyz culture: $5^{\text {th }}$ c. BC $4^{\text {th }}$ c. AD. In: [History of the Bashkir People]. In 7 vols. M. M. Kulsharipov (ed.). Moscow: Nauka, 2009. Pp. 223-245. (In Russ.)

Protsenko A. S. Burial complexes of the Kara-Abyz culture (historical review of the accumulated source base). Klio. 2016. No. 9 (117). Pp. 4347. (In Russ.)

Protsenko A. S. Funeral rites of the Kara-Abyz culture: summarized characteristics. In: $5^{\text {th }}$ $\left(21^{\text {st }}\right)$ All-Russia Congress of Archaeologists]. Coll. papers. Barnaul: Altai State University, 2017. Pp. 854-855. (In Russ.)
Protsenko A. S. On social reconstruction of ancient societies in the archaeology of the Kama Region and the Cis-Urals in the Early Iron Age. Historiographic aspect. In: [Transactions of the Kama Archaeological and Ethnographic Expedition]. Vol. 8. Perm: Perm State Humanitarian-Pedagogical University, 2012. Pp. 177-181. (In Russ.)

Pshenichnyuk A. Kh. Biktimirovo burial ground. In: [Archaeology and Ethnography of Bashkiria]. Vol. II. Ufa: Institute of History, Language and Literature, 1964. Pp. 215-231. (In Russ.)

Pshenichnyuk A. Kh. Kara-Abyz culture: population of central Bashkortostan at dawn of our era. In: [Archaeology and Ethnography of Bashkiria]. Vol. V Ufa: Institute of History, Language and Literature, 1973. Pp. 162-243. (In Russ.)

Vorobyeva S. L. Types of costume complexes of Cara-Abyz culture bearers of Early Iron Age. Archaeology of the Eurasian Steppes. 2019. No. 1. Pp. 50-69. (In Russ.)

Zhuravleva G. N., Baykova A. K. Works of archaeologists of the Kama River region: issues of social structure. In: [Archaeological Heritage of the Urals: from Earliest Discoveries to Fundamental Scientific Knowledge]. Izhevsk: Institute of Computer Science, 2016. Pp. 1820. (In Russ.) 